\title{
Self-efficacy for Self-regulated Learning and Chinese Students' Intention to Use Online Learning in COVID-19: A Moderated Mediation Model
}

\author{
Yajuan Cui
}

\begin{abstract}
Self-efficacy for self-regulated learning (SESRL) is a protective factor for academic performance. However, there are few studies have explored its impact on online learning during the Covid-19. This study investigated (a) the mediating roles of perceived usefulness (PU) and perceived ease of use (PEOU) in the relationship between SESRL and use intention (UI) and (b) the moderating role of gender in the indirect relationship between SESRL and UI. Four hundred Chinese college students entered this study and completed the measurements of SESRL, PEOU, PU and UI. The results showed that SESRL, PEOU, PU and UI were positively correlated with each other. Mediating analysis showed that PEOU and PU mediated the relationship between SESRL and UI. By comparison, the single mediating effect of PEOU was stronger than the single mediating effect of $\mathrm{PU}$ and the multiple mediation of them together, which showed the robust effect of PEOU. Moderation analysis showed that the effects of SESRL on PU and PEOU in females were stronger than in males. A high level of SESRL is more conducive to improving the PU and PEOU of female students, which further influenced their intention to use online learning.
\end{abstract}

Index Terms-Self-efficacy for self-regulated learning, perceived ease of use, perceived usefulness, use intention.

\section{INTRODUCTION}

In order to reduce the spread of Coivd-19, many countries formulated policies to control interpersonal distance, and schools adopted online learning to protect the health of students and teachers [1], [2]. Teachers could conduct synchronous teaching at a specific time through specific media or record videos in advance, and students completed the courses according to their situation [3], [4]. In China, colleges replaced face-to-face courses with online courses to keep education sustainable during the epidemic with tools like Teams, Zoom, and MOOC.

The flexible communication and digital learning resources of online learning make learners experience a particular way of learning and change the traditional relationship between teachers and students. Scholars have found the positive impact of online learning during the epidemic. The constraint of Covid-19 positively influenced students' performance and efficiency in online learning by changing their learning strategies and making learning sustainable [5], [6].

Although online learning has been widely used in colleges,

Manuscript received March 12, 2021; revised June 20, 2021.

Yajuan Cui is with the Institute of Analytical Psychology, City University of Macau, 999078, China (e-mail: cuichenzixian@163.com). the real impact of online learning depends mainly on whether and to what extent students accept it. Some studies have found that college students are not very willing to study in online classes, and many of them propose that they do not want to continue learning online in the future if there is a choice, and they prefer face to face learning [7], [8]. Students experience pressures and difficulties from attitude, emotion, motivation and self-regulation in online learning. Due to the autonomy and self-regulation of online courses, scholars believe that self-regulated learning (SRL) is crucial for successful education during the outbreak of Covid-19 [9]. The effectiveness of online learning depends on students' attitude or personality of autonomous learning rather than the ability to use technical equipment [10]. Students who think they are capable tend to use SRL strategies frequently, such as making plans and managing time and have more intrinsic motivation and less procrastination [11]. Effective learning strategies are helpful to improve academic performance and adapt to learning in an emergency.

Although many studies have discussed the impact of SRL on online learning in Covid-19, few of them considered the role of self-efficacy for self-regulated learning (SESRL). At present, the world is still under the shadow of the epidemic, and it is crucial to find the factors that affect students' willingness to use online learning. This study contributes to the study of online learning during the epidemic period and tries to put forward suggestions on improving students' willingness to use online learning from the perspective of self-regulated learning.

\section{LITERATURE REVIEW}

\section{A. Technology Acceptance Model (TAM)}

Davis (1985) proposed the TAM model based on rational behavior theory and used it to predict and interpret the acceptance and usage in technology applications [12]. The TAM model in Fig. 1 uses perceived usefulness (PU) and perceived ease of use (PEOU) as independent variables, which could influence the behavior of user technology adoption. In addition, TAM uses behavior intention or actual use of the information system as a dependent variable.

PEOU reflects the extent to which users believe that using a particular system would be free of effort, and PU reflects the extent to which users believe that using a system will improve their performance [13]. PEOU and PU are influenced by external factors in the TAM model, including subjective norms, experience, perceived enjoyment, computer anxiety, and self-efficacy [14]. Behavior intention refers to the subjective possibility of a person performing a 
particular act, such as use intention (UI), which is the crucial factor to the success of a system [15], [16]. In the original TAM model, behavior intention was influenced by attitudes, PU, and PEOU.

In online learning, PEOU reflects the extent to which users believe that using online learning systems will be free of effort, and PU reflects the degree to which users believe that using online learning systems will improve their learning performance [17]. Previous studies have confirmed the significant effects of PEOU and PU on use intention and the significant effect of PEOU on PU in online learning among college students [18]-[21]. When students believe the technology is easy to use, they may think that the technology is useful and consider using it.

Many researchers have used TAM to predict and explain the use behavior of online learning. Some of them have tested students' acceptance of online learning in Covid-19 with TAM and demonstrated the influences of internal factors, institutional factors, external factors, PU and PEOU on students' use intention [22]-[25].

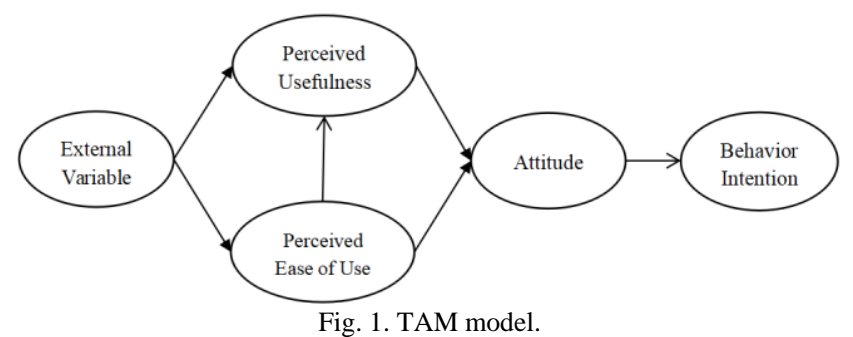

\section{B. Self-efficacy for Self-regulated Learning (SESRL)}

Self-regulated learning refers to self-generated thoughts, feelings, and actions planned and systematically adapted as needed to affect one's learning and motivation [26]. It involves the formulation of learning goals, the monitoring of achieving goals, and the reflection on the usefulness of strategies. Scholars have confirmed the significant prediction of self-regulated learning on students' satisfaction with online education and the moderation effect of self-regulated learning on basic need satisfaction, positive emotion, and intrinsic learning motivation [27], [28]. Learners with a higher level of SRL are positive about their learning effectiveness and have more intrinsic motivation and less procrastination [11], [29].

Understanding self-regulation strategies does not mean that users can use them efficiently. Learners' belief in self-regulation ability is a determinant factor of successful self-regulation, which means that a high level of self-efficacy for self-regulated learning (SESRL) is necessary [30], [31]. Previous studies have noted that SESRL positively affects students' learning [32], [33]. As a belief of self-efficacy, SESRL is positively correlated with students' academic performance and is a predictor of achievement goals [32]. Students who know how to learn and actively participate in learning are not willing to actively cheat [33].

Students with good performance often use many self-regulated learning strategies (e.g., organizing, transforming, and seeking information), which predicts the score of standardized performance tests [34], [35]. Compared with traditional learning methods, online learning needs more self-management and self-efficacy for self-regulated learning. Students who are confident in their learning ability will have more motivation to participate in the learning process and persist in accomplishing arduous academic tasks, which will make them more successful in online learning [36], [37]. Students with a high level of learning self-efficacy tend to use online learning, while those who do not believe their abilities to use technology will avoid using it [38].

In this new era, the construction of knowledge is increasingly dependent on the electronic network. In online learning research, students with a high level of SESRL are prone to use online education and show great strategic flexibility in seeking solutions [39]. They tend to think that using online learning is easy and useful. Therefore, SESRL may positively influence use intention through PEOU and PU.

\section{Gender}

There are gender differences in SESRL, and female students have higher self-efficacy in self-regulation than male students [40], [41]. Female students expressed a high degree of confidence in their ability to make homework plans, retrieve information provided in classes or textbooks, and participate in class discussions [40]. Scholars investigated the gender differences in academic self-regulation behaviors and found that female students showed more goal's setting, planning and self-monitoring than male students [42]. The effects of SESRL on PU and PEOU in females may be stronger than those in males.

\section{ThE PRESENT STUDY}

Based on previous studies, SESRL may affect users' practical evaluation and intention to use online learning. People with a high level of SESRL are prone to think online learning is easy and useful, improving their intention to use it. Therefore, this study explored the Chinese college students' intention to use online learning during the epidemic by taking SESRL as the external influencing factor, PU and PROU as the mediating variables, and gender as a moderating variable (as shown in Fig. 2).

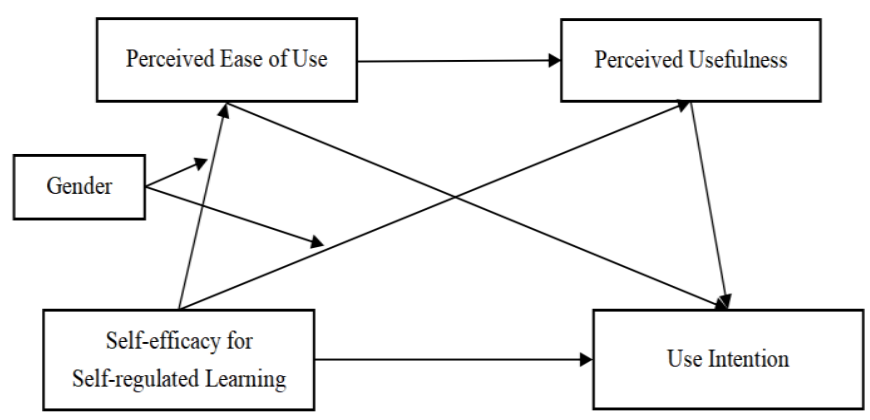

Fig. 2. Structural model.

This study proposed the following assumptions:

H1: Perceived usefulness and perceived ease of use could mediate the relationship between SESRL and use intention.

$\mathrm{H} 2$ : Gender could moderate the effects of SESRL on perceived usefulness and perceived ease of use. 


\section{METHOD}

\section{A. Participants}

This study was conducted from April to June 2020, and the participants were Chinese college students who studied in online courses during Covid-19. This research was introduced on the campus social platform of universities in Macau, and students were invited to participate. Since the students were at home, this study sent the questionnaires to them through the Internet. Four hundred and forty-two participants voluntarily entered and completed the questionnaires online. After eliminating the invalid data, the number of valid questionnaires was four hundred, with an effective rate of $90 \%$. There were one hundred and fifty-four males, and two hundred and forty-six females, with an average age of 21.15 years $(\mathrm{SD}=1.58)$.

\section{B. Measure}

Demographic information. It included age, gender, and other information. It also asked participants if they were participating in the school's online courses. Only the questionnaire with a "Yes" answer was valid.

Self-efficacy for self-regulated learning. The scale of SESRL was compiled by Zimmerman, Bandura and Martinez-Pons (1992) and revised by Wang and Qian (2015) with 11 items [43], [44]. The scale used a 7-Likert scale with 1 representing "extremely bad" and 7 representing "extremely good". The Cronbach's $\alpha$ of scale is 0.83 , indicating excellent reliability.

Perceived usefulness, perceived ease of use and use intention. This study adapted the measures of Venkatesh and Davis (2000) to form three scales to measure PU, PEOU and use intention. Each scale contained three items with a 5 -scoring system with 1 representing "extremely disagree" and 5 representing "extremely agree".

\section{Procedure}

Firstly, this study verified the reliability and validity of the measurements. Secondly, all variables were standardized, and the Process macro invented by Hayes (2013) was used to test the mediating effect. Thirdly, this study encoded gender and used Process macro to test whether the mediating process was moderated by gender. In addition, the bootstrapping method with 5000 data resampling tested the significance of mediating effects with the $95 \%$ bias-corrected confidence interval.

\section{RESULT}

\section{A. Reliability and Validity Analysis}

Table I and Table II presented the results of validity and reliability. Cronbach's $\alpha$ coefficient of reliability was equal to or greater than 0.7 , indicating good reliability. Convergent validity could be measured by standardized factor loading, Average Variance Extracted (AVE) and Composite Reliability (CR). Standardized factor loadings of all items were greater than 0.6, the values of AVE were greater than 0.5 , and the values of CR were greater than 0.7 , which indicated the good convergence validity of scales. For each variable, the square root of AVE was greater than the correlation coefficient, showing good discriminant validity.

TABLE I: TEST OF RELIABILITY AND VALIDITY

\begin{tabular}{|c|c|c|c|c|c|}
\hline $\begin{array}{c}\text { Construct } \\
\mathrm{s}\end{array}$ & Items & $\begin{array}{l}\text { Standardized } \\
\text { loadings }\end{array}$ & Alpha & $\mathrm{CR}$ & AVE \\
\hline \multirow{3}{*}{ PEOU } & PEOU1 & 0.83 & \multirow{3}{*}{0.81} & \multirow{3}{*}{0.89} & \multirow{3}{*}{0.73} \\
\hline & PEOU2 & 0.85 & & & \\
\hline & PEOU3 & 0.88 & & & \\
\hline \multirow{3}{*}{$\mathrm{PU}$} & PU1 & 0.86 & \multirow{3}{*}{0.70} & \multirow{3}{*}{0.85} & \multirow{3}{*}{0.65} \\
\hline & PU2 & 0.85 & & & \\
\hline & PU3 & 0.70 & & & \\
\hline \multirow{3}{*}{ UI } & UI1 & 0.85 & \multirow{3}{*}{0.83} & \multirow{3}{*}{0.90} & \multirow{3}{*}{0.75} \\
\hline & UI2 & 0.87 & & & \\
\hline & UI3 & 0.88 & & & \\
\hline \multirow{11}{*}{ SESRL } & SESRL1 & 0.87 & \multirow{11}{*}{0.97} & \multirow{11}{*}{0.97} & \multirow{11}{*}{0.74} \\
\hline & SESRL2 & 0.86 & & & \\
\hline & SESRL3 & 0.89 & & & \\
\hline & SESRL4 & 0.86 & & & \\
\hline & SESRL5 & 0.85 & & & \\
\hline & SESRL6 & 0.87 & & & \\
\hline & SESRL7 & 0.89 & & & \\
\hline & SESRL8 & 0.87 & & & \\
\hline & SESRL9 & 0.83 & & & \\
\hline & $\begin{array}{c}\text { SESRL1 } \\
0\end{array}$ & 0.85 & & & \\
\hline & $\begin{array}{c}\text { SESRL1 } \\
1\end{array}$ & 0.82 & & & \\
\hline
\end{tabular}

$\overline{\text { Note: Self-efficacy for self-regulated learning (SESRL), Perceived ease of }}$ use (PEOU), Perceived usefulness (PU), Use Intention (UI)

TABLE II: CORRELATION ANALYSIS

\begin{tabular}{|c|c|c|c|c|c|}
\hline $\begin{array}{c}\text { Construct } \\
\mathrm{s} \\
\end{array}$ & $\mathrm{M} \pm \mathrm{SD}$ & 1 & 2 & 3 & 4 \\
\hline 1.SESRL & $5.51 \pm 1.29$ & 0.86 & & & \\
\hline 2.PEOU & $4.02 \pm 0.80$ & $0.65 * *$ & 0.85 & & \\
\hline 3.PU & $3.88 \pm 0.85$ & $0.56^{* *}$ & $0.67 * *$ & 0.81 & \\
\hline 4.UI & $3.98 \pm 0.82$ & $0.62 * *$ & $0.75^{* *}$ & $0.66^{* *}$ & 1 \\
\hline
\end{tabular}

\section{B. Testing for Mediation Effect}

Table II listed the mean, standard deviation and correlation of each variable. As expected, there were positive relationships between SESRL, PEOU, PU, and use intention.

This study standardized the average score of all variables and used Process macro (Model 6) to analyze the mediating effects of PEOU and PU on the relationship between SESRL and use intention. Fig. 3 showed the test results of mediation. First, the overall effect of SESRL on use intention was significant $(\beta=0.62, p<0.001)$. Second, the effects of SESRL on PEOU and PU were significant $(\beta=0.65, p<0.001 ; \beta=0.22$, $P<0.001)$. The PEO, as the first mediator, significantly affected PU that was the second mediator $(\beta=0.53, p<0.001)$. Third, PEOU and PU had significant direct effects on use intention $(\beta=0.48, P<0.001 ; \beta=0.24, P<0.001)$. Fourth, when PEOU and PU entered the equation simultaneously, the significant relationship between SESRL and use intention decreased $(\beta=0.16, p<0.01)$.

The bootstrapping method with 5000 collected samples tested the significance of mediating effect in a $95 \%$ confidence interval (Table III). The total indirect effect of SESRL on use intention was statistically significant because 
the $95 \%$ confidence interval did not contain $0\left(\mathrm{CI}_{95 \%}[0.35\right.$, 0.56]). The mediation effects of PEOU and PU were statistically significant. The single mediation effects of PEOU and PU were significant $\left(\mathrm{CI}_{95 \%}[0.23,0.42], \mathrm{CI}_{95 \%}\right.$ $[0.02,0.09])$, and multiple mediation effects of them together were also significant $\left(\mathrm{CI}_{95 \%}[0.04,0.13]\right)$. In order to find out the differences between single mediation and multiple mediation, this study compared the indirect effects. The results shown in Table III showed that the single mediating effect of PEOU was stronger than the single mediating effect of PU $\left(\mathrm{CI}_{95 \%}[0.16,0.37]\right)$ and the multiple mediation of them together $\left(\mathrm{CI}_{95 \%}[0.13,0.35]\right)$. There was no significant difference between the single mediation effect of PU and the multiple mediation effect of PU and PEOU together $\left(\mathrm{CI}_{95 \%}\right.$ $[-0.08,0.01])$.

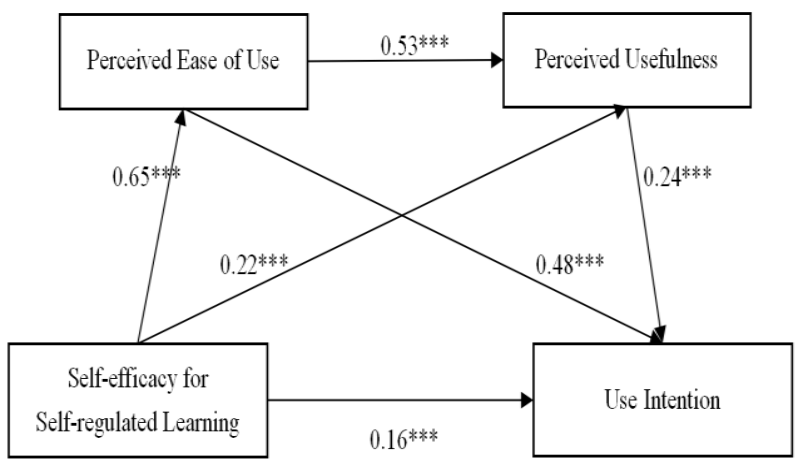

Note: $* * * p<0.001, * * p<0.01, * p<0.05$

Fig. 3. Structural model.

TABLE III: MEDIATION EFFECT ANALYSIS

\begin{tabular}{cccccc}
\hline \hline Effect & $\begin{array}{c}\text { Point } \\
\text { Estimate }\end{array}$ & $\begin{array}{c}\text { Boot } \\
\text { SE }\end{array}$ & $\begin{array}{c}\text { Boot } \\
\text { LLCI }\end{array}$ & $\begin{array}{c}\text { Boot } \\
\text { ULCI }\end{array}$ & $\begin{array}{l}\text { Relative } \\
\text { Ind. } \\
\text { Effect }\end{array}$ \\
\hline $\begin{array}{c}\text { Total Ind. } \\
\text { Effect }\end{array}$ & 0.45 & 0.05 & 0.35 & 0.56 & $72.84 \%$ \\
\hline Ind1 & 0.31 & 0.05 & 0.23 & 0.42 & $50.79 \%$ \\
\hline Ind2 & 0.05 & 0.02 & 0.02 & 0.09 & $8.53 \%$ \\
\hline Ind3 & 0.08 & 0.02 & 0.04 & 0.13 & $13.52 \%$ \\
\hline Ind1 vs Ind2 & 0.26 & 0.05 & 0.16 & 0.37 & \\
\hline Ind1 vs Ind3 & 0.23 & 0.06 & 0.13 & 0.35 & \\
\hline Ind2 vs Ind3 & -0.03 & 0.02 & -0.08 & 0.01 & \\
\hline \hline
\end{tabular}

Boot SE: Standard error of Bootstrap.

Boot CILL: The lower limit of $95 \%$ confidence interval.

Boot CIUL: The upper limit of $95 \%$ confidence interval.

Relative Indirect Effect: Indirect effect / total effect.

Ind1: $S E S R L \rightarrow P E O U \rightarrow U I$.

Ind2: $S E S R L \rightarrow P U \rightarrow U I$.

Ind3: $S E S R L \rightarrow P E O U \rightarrow P U \rightarrow U I$.

\section{Testing for Moderated Mediation}

This study coded gender with " 0 " representing males and "1" representing females. Process macro (Model 84) was used to analyze the moderation effect of gender between SESRL and use intention.

In Table IV, Model 1 showed that gender moderated the relationship between SESRL and PEOU $(\beta=0.21, p<0.01)$. Model 2 showed that gender moderated the relationship between SESRL and PU $(\beta=0.19, p<0.05)$.

This study mapped the chart of PEOU and PU predicted by SESRL in males and females, respectively (Fig. 4 and Fig. 5). The simple slope test in Fig. 4 showed that for female students, SESRL was positively correlated with PEOU $\left(\beta_{\text {simple }}=0.71, p<0.001\right)$. For male students, SESRL was positively correlated with PEOU $\left(\beta_{\text {simple }}=0.50, p<0.001\right)$, but the correlation was weaker compared to female students.

The simple slope test in Fig. 5 showed that for female students, SESRL was positively correlated with PU $\left(\beta_{\text {simple }}=0.28, p<0.001\right)$. For male students, SESRL was not related to $\mathrm{PU}\left(\beta_{\text {simple }}=0.09, p>0.05\right)$.

TABLE IV: MODERATION EFFECT ANALYSIS

\begin{tabular}{|c|c|c|c|c|c|c|}
\hline \multirow{2}{*}{$\begin{array}{c}\text { Predictor } \\
\text { S } \\
\end{array}$} & \multicolumn{2}{|c|}{ Mode 1 (PEOU) } & \multicolumn{2}{|c|}{ Mode 2(PU) } & \multicolumn{2}{|c|}{ Mode 3 (IU) } \\
\hline & $\beta$ & $t$ & $\beta$ & $t$ & $\beta$ & $t$ \\
\hline SESRL & 0.50 & $\begin{array}{l}7.50 * * \\
*\end{array}$ & 0.09 & 1.24 & 0.16 & $3.95 * * *$ \\
\hline Gender & -0.17 & $-2.16^{*}$ & 0.19 & $2.60 * *$ & & \\
\hline $\begin{array}{c}\text { SESRL } \times \\
\text { Gender }\end{array}$ & 0.21 & $2.62 * *$ & 0.19 & $2.51 *$ & & \\
\hline PEOU & & & 0.53 & $11.14 * * *$ & 0.48 & $10.47 * * *$ \\
\hline PU & & & & & 0.24 & $5.69 * * *$ \\
\hline $\mathrm{R}^{2}$ & & 44 & & 0.50 & & 0.63 \\
\hline $\mathrm{F}$ & & 3.39 & & 98.11 & & 21.83 \\
\hline
\end{tabular}

Note: $* * * p<0.001, * * p<0.01, * p<0.05$.

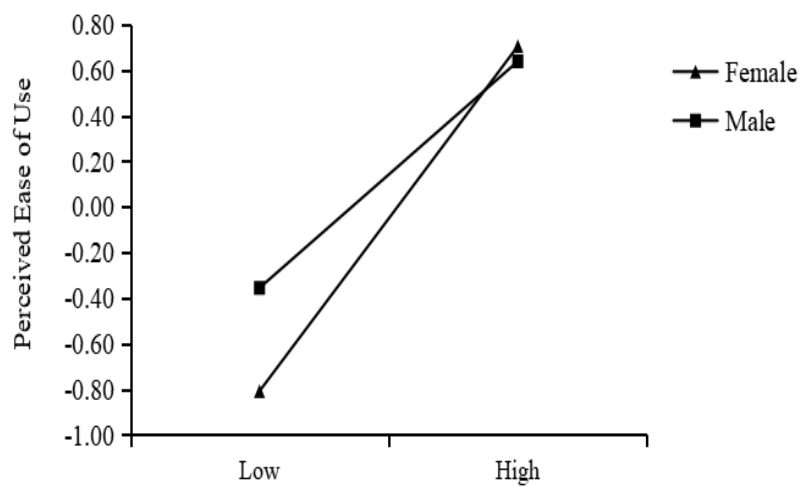

Self-efficacy of Self-regulated Learning

Fig. 4. Simple slope plot of perceived ease of use.

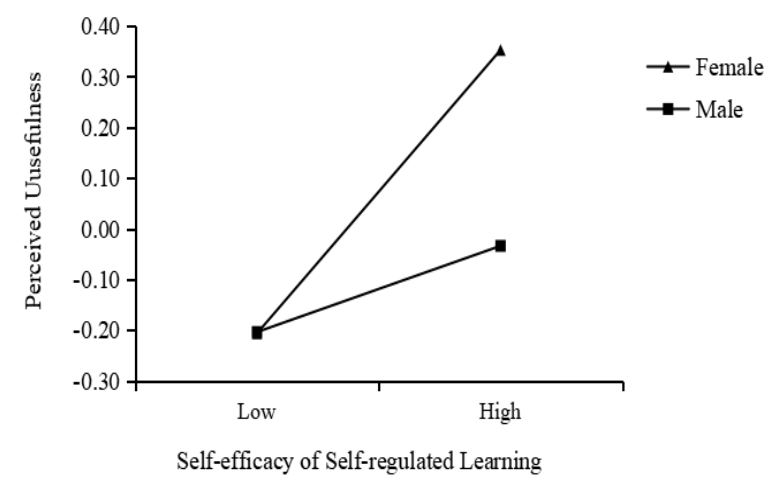

Fig. 5. Simple slope plot of perceived usefulness.

\section{DISCUSSION}

Based on the TAM model, this study established a moderated mediation model to test whether SESRL could affect college students' intention to use online learning through PU and PEOU and whether this indirect relationship could be moderated by gender.

This study verified the positive effect of SESRL on college 
students' intention to use online learning. The results showed that students with a high level of SESRL were more likely to use online learning. Scholars have found the protective effect of SESRL on learning and achievements [32], [33]. Students with a high level of SESRL tend to make good use of online learning with self-regulated learning strategies, such as organizing, transforming, and seeking information [34]. Therefore, it is suggested that teachers improve students' SESRL and cultivate their strategies for self-regulated learning, such as search contests and use training, which could encourage them to actively use the convenient resources of online learning and increase their use intention.

The results of mediation analysis showed that PEOU and PU mediated the effect of SESRL on use intention. Students with a high level of SESRL often have flexible strategies in finding solutions, such as planning and managing academic work, establishing an efficient learning environment, and getting rid of distractions [35], [39]. A high degree of confidence and awareness of self-ability could affect students' utilization and mastery of online learning. When students think it is easy to use online learning, they are more likely to believe that it is useful and then prefer to use it.

The comparison of mediation effects showed that the single mediation effect of PEOU was stronger than the single mediation effect of PU and the multiple mediation of them together, which means that the mediation effect of PEOU on SESRL and use intention was greater than that of PU. PEOU was an essential influencing factor in the relationship between SESRL and use intention.

The results of moderating effect analysis showed that gender played a moderating role in the first stage of the mediation model. The positive effect of SESRL on PEOU was moderated by gender, and the effect was stronger in females than in males. The positive effect of SESRL on PU was significant in females but not significant in males. Previous studies have shown that female students have higher confidence in self-regulation than male students [40]. Female students expressed a high degree of confidence in their ability to make homework plans, retrieve information provided in classes or textbooks, and participate in class discussions. Female students showed more goal setting, planning and self-monitoring than male students in academic self-regulation behaviors [42]. These behavioral strategies may improve their evaluation of the usefulness and ease of use in online learning. Therefore, SESRL has a more significant impact on PEOU and PU in female students than male students.

\section{CONCLUSION}

The results showed that perceived usefulness and perceived ease of use could mediate the effect of self-efficacy for self-regulated learning on students' intention to use online learning. In other words, self-efficacy for self-regulated learning positively affected students' perceived usefulness and perceived ease of use, which further increases their intention to use online learning. In addition, the first stage of the mediation model (from self-efficacy for self-regulated learning to perceived usefulness and perceived ease of use) was moderated by gender. For college students, the effects of self-efficacy for self-regulated learning on perceived usefulness and perceived ease of use were more robust in female students than in male students.

\section{CONFLICT OF INTEREST}

The author declares no conflict of interest.

\section{AUTHOR CONTRIBUTIONS}

The author's contribution to this work includes: conducting research, analyzing data and writing the paper.

\section{ACKNOWLEDGMENT}

The research was conducted with support and suggestion from teachers and students of the City University of Macau. The author thanks all the participants for their enthusiasm and dedication. With their help, the author designed and completed the study.

\section{REFERENCES}

[1] M. Mailizar, D. Burg, and S. Maulina, "Examining university students" behavioral intention to use e-learning during the COVID-19 pandemic: An extended TAM model," Education and Information Technologies, pp. 1-21, April 2021.

[2] W. Cao, Z. Fang, G. Hou, M. Han, X. Xu, J. Dong, and J. Zheng, "The psychological impact of the COVID-19 epidemic on college students in China," Psychiatry Research, vol. 287, May 2020.

[3] J. Crawford, K. Butler-Henderson, J. Rudolph, B. Malkawi, M. Glowatz, R. Burton, and S. Lam, "COVID-19: 20 countries' higher education intra-period digital pedagogy responses," Journal of Applied Learning and Teaching, vol. 3, pp. 1-20, March 2020

[4] C. Hodges, S. Moore, B. Lockee, T. Trust, and A. Bond, "The difference between emergency remote teaching and online learning," Educause Review, vol. 27, pp. 1-12, March 2020.

[5] M. A. Gonzalez, D. L. Rubia, K. P Hincz, M. Comas-Lopez, L. Subirats, S. Fort, and G. M. Sacha, "Influence of COVID-19 confinement on students' performance in higher education," PloSone, vol. 15, October 2020.

[6] S. Iglesias-Pradas, Á. Hernández-García, J. Chaparro-Peláez, and J. L. Prieto, "Emergency remote teaching and students' academic performance in higher education during the COVID-19 pandemic: A case study," Computers in Human Behavior, vol. 119, June 2021.

[7] A. P. Aguilera-Hermida, "College students' use and acceptance of emergency online learning due to Covid-19," International Journal of Educational Research Open, vol. 1, September 2021.

[8] D. Chung, G. Subramaniam, and L. C. Dass, "Online Learning Readiness among University Students in Malaysia amidst COVID-19," Asian Journal of University Education, vol. 16, pp. 46-58, July 2020.

[9] D. Sulisworo, M. Fitrianawati, I. Maryani, S. Hidayat, E. Agusta, and W. Saputri, "Students' self-regulated learning (SRL) profile dataset measured during Covid-19 mitigation in Yogyakarta," Indonesia. Data in Brief, vol. 33, p. 106422, December 2020.

[10] W. Bao, "COVID-19 and online teaching in higher education: A case study of Peking University," Human Behavior and Emerging Technologies, vol. 2, pp. 113-115, April 2020.

[11] E. R. Pelikan, M. Lüftenegger, J. Holzer, S. Korlat, C. Spiel, and B. Schober, "Learning during COVID-19: The role of self-regulated learning, motivation, and procrastination for perceived competence," Zeitschrift für Erziehungswissenschaft, vol. 24, pp. 393-418, March 2021.

[12] E. D. Davis, "A technology acceptance model for empirically testing new end-user information systems: Theory and results," Ph.D. dissertation, Dept. Elect. Eng, MIT, Boston, USA, 1985.

[13] F. D. Davis, "Perceived usefulness, perceived ease of use, and user acceptance of information technology," MIS Quarterly, vol. 13, pp. 319-340, September 1989.

[14] F. Abdullah and R. Ward, "Developing a general extended technology acceptance model for e-learning (GETAMEL) by analysing commonly used external factors," Computers in Human Behavior, vol. 56, pp 238-256, March 2016. 
[15] M. Fishbein and I. Ajzen, Belief, Attitude, Intention, and Behavior: An Introduction to Theory and Research, Reading, MA: Addison-Wesley, 1975.

[16] C. T. Chang, J. Hajiyev, and C. R. Su, "Examining the students' behavioral intention to use e-learning in Azerbaijan? The general extended technology acceptance model for e-learning approach,' Computers and Education, vol. 111, pp. 128-143, August 2017.

[17] P. C. Sun, R. J. Tsai, G. Finger, Y. Y. Chen, and D. Yeh, "What drives a successful e-Learning? An empirical investigation of the critical factors influencing learner satisfaction," Computers and Education, vol. 50, pp. 1183-1202, May 2008.

[18] Y. C. Lee, "An empirical investigation into factors influencing the adoption of an e-learning system," Online Information Review, vol. 30 , pp. 517-541, September 2006.

[19] M. R. Martínez-Torres, S. L. Toral Marín, F. B. García, S. G. Vázquez, M. A. Oliva, and T. Torres, "A technological acceptance of e-learning tools used in practical and laboratory teaching, according to the European higher education area," Behavior and Information Technology, vol. 27, pp. 495-505, November 2008.

[20] S. S. Binyamin, M. J. Rutter, and S. Smith, "Extending the technology acceptance model to understand students' use of learning management systems in Saudi higher education," International Journal of Emerging Technologies in Learning, vol. 14, pp. 4-21, February 2019.

[21] F. Abdullah, R. Ward, and E. Ahmed, "Investigating the influence of the most commonly used external variables of TAM on students' perceived ease of use (PEOU) and perceived usefulness (PU) of e-portfolios," Computers in Human Behavior, vol. 63, pp. 75-90, May 2016.

[22] A. Alfadda and H. S. Mahdi, "Measuring students' use of zoom application in language course based on the technology acceptance model (TAM)," Journal of Psycholinguistic Research, pp. 1-18, January 2021.

[23] G. Maheshwari, "Factors affecting students' intentions to undertake online learning: An empirical study in Vietnam," Education and Information Technologies, pp. 1-21, March 2021.

[24] C. S. L. M. Lazim, N. D. B. Ismail, and M. D. A. K. Tazilah, "Application of technology acceptance model (TAM) towards online learning during covid-19 pandemic: Accounting students perspective," Int. J. Bus. Econ. Law, vol. 24, pp. 13-20, February 2021.

[25] H. Baber, "Modelling the acceptance of e-learning during the pandemic of COVID-19 - A study of South Korea," The International Journal of Management Education, vol. 19, p. 100503, July 2021.

[26] B. J. Zimmerman and D. H. Schunk, Models of Self-regulated Learning and Academic Achievement, Springer New York, 1989.

[27] K. M. Hamdan, A. M. Al-Bashaireh, Z. Zahran, A. Al-Daghestani, and A. M. Shaheen, "University students' interaction, internet self-efficacy, self-regulation and satisfaction with online education during pandemic crises of covid-19 (sars-cov-2)," International Journal of Educational Management, Ahead-of-Print, January 2021.

[28] J. Holzer, M. Lüftenegger, S. Korlat, E. Pelikan, K. Salmela-Aro, C. Spiel, and B. Schober, "Higher education in times of COVID-19: University students' basic need satisfaction," Self-regulated Learning, and Well-Being, AERA Open, vol. 7, p. 233285842110031, March 2021.

[29] J. C. Hong, Y. F. Lee, and J. H. Ye, "Procrastination predicts online self-regulated learning and online learning ineffectiveness during the coronavirus lockdown," Personality and Individual Differences, vol. 174, pp. 110673, May 2021.

[30] B. J. Zimmerman and T. J. Cleary, "Adolescents' development of personal agency: The role of self-efficacy beliefs and self-regulatory skill," Self-efficacy Beliefs of Adolescents, vol. 5, pp. 45-69, January 2006.

[31] E. L. Usher and F. Pajares, "Self-efficacy for self-regulated learning: A validation study," Educational and Psychological Measurement, vol. 68 , pp. 443-463, November 2008.
[32] H. Agustiani, S. Cahyad, and M. Musa, "Self-efficacy and self-regulated learning as predictors of students academic performance," The Open Psychology Journal, vol. 9, pp. 1-6, February 2016.

[33] V. Putarek and N. Pavlin-Bernardić, "The role of self-efficacy for self-regulated learning, achievement goals, and engagement in academic cheating," European Journal of Psychology of Education, vol. 35, pp. 647-671, November 2019.

[34] B. J. Zimmerman and M. M. Pons, "Development of a structured interview for assessing student use of self-regulated learning strategies," American Educational Research Journal, vol. 23, pp. 614-628, January 1986.

[35] B. J. Zimmerman and M. Martinez-Pons, "Construct validation of a strategy model of student self-regulated learning," Journal of Educational Psychology, vol. 80, p. 284, September 1988.

[36] R. J. Chu and A. Z. Chu, "Multi-level analysis of peer support, Internet self-efficacy and e-learning outcomes - The contextual effects of collectivism and group potency," Computers and Education, vol. 55, pp. 145-154, August 2010.

[37] K. Barnard-Brak, O. V. Paton, and W. Y. Lan, "Profiles in self-regulated learning in the online learning environment," International Review of Research in Open and Distributed Learning, vol. 11, pp. 61-80, March 2010.

[38] J. Mallya, S. Lakshminarayanan, and V. Payini, "Self-efficacy as an antecedent to students' behavioral intention to use the Internet for academic purposes: A structural equation modeling approach," Libr. Philos. Pract, vol. 1-12, September 2019.

[39] Y. J. Joo, M. Bong, and H. J. Choi, "Self-efficacy for self-regulated learning, academic self-efficacy, and Internet self-efficacy in Web-based instruction," Educational Technology Research and Development, vol. 48, pp. 5-17, 2000.

[40] F. Pajares, "Gender and perceived self-efficacy in self-regulated learning," Theory into Practice, vol. 41, pp. 116-125, Spring, 2002.

[41] G. V. Caprara, R. Fida, M. Vecchione, G. Del Bove, G. M. Vecchio, C. Barbaranelli, and A. Bandura, "Longitudinal analysis of the role of perceived self-efficacy for self-regulated learning in academic continuance and achievement," Journal of Educational Psychology, vol. 100, pp. 525-534, August 2008

[42] B. J. Zimmerman and M. Martinez-Pons, "Student differences in self-regulated learning: Relating grade, sex, and giftedness to self-efficacy and strategy use," Journal of Educational Psychology, vol. 82, pp. 51-59, March 1990.

[43] B. J. Zimmerman, A. Bandura, and M. Martinez-Pons, "Self-motivation for academic attainment: The role of self-efficacy beliefs and personal goal setting," American Educational Research Journal, vol. 29, pp. 663-676, January 1992.

[44] M. Wang and M. Y. Qian, "The Chinese revision of self-efficacy of self-regulated learning scale," China Journal of Health Psychology, vol. 23, pp. 1532-1536, October 2015.

Copyright (C) 2021 by the authors. This is an open access article distributed under the Creative Commons Attribution License which permits unrestricted use, distribution, and reproduction in any medium, provided the original work is properly cited (CC BY 4.0).

Yajuan Cui is a PhD. candidate in psychology at the City University of Macau. She is a psychological consultant in China, working in mental health education and counseling. Her research interests are psychological analysis and mental health education for college students. She searches for self and understands the meaning of life through systematic study of psychoanalysis, such as sandplay and dream work. Based on Chinese culture, she applies psychological counseling to education, using its important effect in social culture, art and a wide range of humanities and social sciences. She is committed to helping students' psychological development and improving their mental health with psychological education. 